The University of San Francisco

USF Scholarship: a digital repository @ Gleeson Library |

Geschke Center

Kinesiology (Formerly Exercise and Sport Science)

College of Arts and Sciences

2004

\title{
NBA Expansion and Relocation: A Viability Study of Various Cities
}

Daniel A. Rascher

University of San Francisco, RASCHER@USFCA.EDU

Heather Rascher

Follow this and additional works at: http://repository.usfca.edu/ess

Part of the Sports Management Commons

\section{Recommended Citation}

Rascher, Daniel A. and Rascher, Heather, "NBA Expansion and Relocation: A Viability Study of Various Cities" (2004). Kinesiology (Formerly Exercise and Sport Science). Paper 2.

http://repository.usfca.edu/ess/2

This Article is brought to you for free and open access by the College of Arts and Sciences at USF Scholarship: a digital repository @ Gleeson Library | Geschke Center. It has been accepted for inclusion in Kinesiology (Formerly Exercise and Sport Science) by an authorized administrator of USF Scholarship: a digital repository@ Gleeson Library | Geschke Center. For more information, please contact repository@usfca.edu. 


\title{
NBA Expansion and Relocation: A Viability Study of Various Cities
}

\author{
Daniel Rascher \\ University of San Francisco
}

\section{Heather Rascher SportsEconomics}

\begin{abstract}
An examination of possible expansion or relocation sites for the NBA is undertaken using a two-equation system requiring two-stage probit least squares to estimate. The location model forecasts the best cities for an NBA team based on the underlying characteristics of current NBA teams. The results suggest that Louisville, San Diego, Baltimore, St. Louis, and Norfolk appear to be the most promising candidates for relocation or expansion.
\end{abstract}

Regardless of the state of the economy, many cities continue to pursue bigleague sports franchises so they will locate in their metropolitan area. For instance, Louisville has been trying to lure a National Basketball Association (NBA) franchise for more than 7 years. More recently, New Orleans was successful in attracting the former Charlotte Hornets to move into a new arena in the city. ${ }^{1}$ Both Northern Virginia and Washington, DC, are currently looking to house a Major-League Baseball (MLB) team. Moreover, Paul Allen was interested in bringing a National Hockey League (NHL) or MLB team to the city of Portland, WA, in an effort to provide content for his regional sports network.

Professional basketball began in the United States in 1946 with eleven teams, three of which are still in existence. Some teams have gone out of business whereas others have moved to different cities and have changed names. ${ }^{2}$ Instances of relocation, however, are infrequent. Some of the recent team relocations include the Golden State Warriors' move from San Francisco to Oakland (1971); the Rockets' move from San Diego to Houston (1971); the Wizards' move to Washington in 1974 (renamed the Wizards in 1997 from the Washington Bullets); the Nets' move to New Jersey (East Rutherford) from New York (1977); the Jazz's move from New Orleans to Salt Lake City (1979); the Clippers' move to Los Angeles from San Diego (1984); and the Kings' move to Sacramento from Kansas City (1985). ${ }^{3}$

Rascher is with the University of San Francisco, Sport Management Program, 2130 Fulton Street, San Francisco, CA 94117-1080. H. Rascher is with SportsEconomics, 110 Brookside Dr., Berkeley, CA 94705. 
The Vancouver Grizzlies' move in 2001 to Memphis (over cities such as Louisville, St. Louis, and New Orleans) and the aforementioned Hornets' move to New Orleans are the most recent relocations.

One key impetus for relocation is to increase arena-related team revenues. Some owners argue that the increased revenues from a new arena will put a franchise in a better position to bid for quality players, resulting in a better team, which, in turn, draws more fans, resulting in more revenues, and so on. The type of sports facility and lease arrangements are as important as the quality of the market in an owner's location decision.

For instance, in the NFL a few teams have recently relocated to smaller markets in order to play in a new stadium with a "sweetheart" lease agreement, in which the teams are offered more favorable stadium deals in order to entice them to relocate. In 1995, the Raiders moved from Los Angeles (the second largest market in the U.S.) back to Oakland, and the Rams moved from Los Angeles to St. Louis. In 1996, the Browns moved to Baltimore to become the Ravens, and the Oilers moved to Tennessee from Houston (becoming the Titans) the following year. ${ }^{4}$ In each of these cases, the new market was smaller (in terms of population) than the previous market. Moreover, the Hornets move from Charlotte to New Orleans was primarily because of a more appealing facility agreement with New Orleans for a state-of-the-art facility; the relocation, however, placed the team in a smaller media market and a less affluent city. ${ }^{5}$

Team relocations, and the threat thereof, have commensurately increased the value of major league clubs. The Oakland A's and Montreal Expos (MLB), the Minnesota Vikings (NFL), and numerous NHL franchises are also considering new locations. This is primarily because of the fact that the four major sports leagues control the supply of teams, the placement of franchises, and the number of teams that are permitted to locate in any market. In spite of demand, the leagues are reluctant to increase the rate of expansion-team creation. In fact, since the NFL and AFL merged in 1966, the NFL has added only seven additional teams, even though several markets desire franchises. ${ }^{6}$

Which cities should teams choose when considering their ideal locale? The choice of a city depends on at least three major factors: the owner's personal preference, the political climate, and the economics of the location. Whereas many team owners are profit maximizers and make decisions accordingly, some owners might be more personally motivated, perhaps choosing to move a team to a city because it is where they live. For instance, Georgia Frontiere, owner of the St. Louis Rams, moved the team from Los Angeles to her hometown of St. Louis, MO. Similarly, the Minnesota Vikings are considering a move to San Antonio, TX, because owner Billy Joe "Red" McCombs is from San Antonio. ${ }^{7}$ Personal preference, as in these cases, is idiosyncratic and will therefore not be investigated in this analysis.

Political support for a major league team in a city is very important because arenas and stadiums are often financed in part or in full by local governments. ${ }^{8}$ The locational decision is usually the result of a bidding competition among the governments of various cities, each offering a variety amenities to the teams in order 
to attract the team to their locale. In fact, the moves by the Oilers, Rams, and Raiders were all to smaller markets, but the stadium leases were more favorable in these markets, despite the reduced population of their new locations.

Finally, the economics of the market matters. Regions with larger, richer populations and those that contain large businesses or numerous corporate headquarters are assumed to more readily support a team than a smaller city that lacks these desirable demographic features. The three overarching decision criteria, however, can be interrelated. For instance, the degree of public funding is likely to correspond to the size and economic demographics of the market. In fact, there is a correlation of .33 (significant at the 1\% level) between the percentage of public funding and the population for six cities with NBA teams that are in relatively smaller population centers. In addition, an owner's preferences are likely to be in favor of locating in a large metropolitan area because of the potential favorable economics.

This article analyzes the economics of each potential market to determine which cities are likely to be the best prospects for expansion or relocation of NBA teams. A hierarchical two-equation system is employed. In the first equation of the location model, the 25 current U.S. markets that have NBA franchises are examined to determine the relationship among the underlying factors. ${ }^{9}$ It is then used to forecast the relative likelihood of other cities being similar enough to NBA cities to be able to support a team (again based on economic factors, not personal preference or political factors). This model is similar to the analysis for baseball teams by Bruggink and Zamparelli (1999), except that the NBA model has additional variables, two stages, and uses a substantially different econometric approach.

The second equation is a revenue equation. The revenue forecasts generated are used as inputs into the first equation. The logic is that the potential revenues that each location could generate are certainly important factors in an owner's location decision.

One objective of the overall analysis is to be able to aid in the financial decision regarding league expansion or team relocation. The current methodology used in the field involves separate comparisons of cities by population and a few other measures, as opposed to an integrated approach that captures the relationships between the factors and relative importance of each. A set of models such as described in this article can be used to rank cities for further, more in-depth analysis, across many sports and in many countries.

The next section examines the basic theory underlying the analysis. The data, data sources, and limitations are described in the third section. The analysis and results for the two-equation system is presented in the fourth section, and the final section provides a summary and a discussion of the results.

\section{Theoretical Model}

The location model is a franchise model based on the work, most recently, of Benjamin Klein (1995). Owners of franchises in the same company have the incentive and desire to locate at least some minimum geographic distance away from 
each other, but want to maintain similarity in terms of quality and products offered in order to reduce uncertainty for customers. For instance, Domino's Pizza franchises are not allowed to locate near each other unless they are owned by the same franchisee.

Sports teams (or franchises) operate in a similar manner, and each of the leagues has developed rules regarding franchise movement and location. In the NBA, an area with a radius of 75 miles surrounds each NBA team and no other NBA team is permitted to locate within that radius without permission of the incumbent team. To understand the rationale as to why NBA teams chose their current locations, the location model takes into consideration the information available from current teams and uses that data to determine the common underlying economic factors of existing NBA locations. The cities currently without NBA teams are then evaluated based on those factors. In order to discern between successful locations of current NBA teams and less successful ones, the revenue equation in the location model accounts for the relative success of each location.

The general model is Location $=f$ (market characteristics, revenue potential, political support, owner preferences) and Revenue Potential $=g$ (market characteristics, team characteristics). Market characteristics contain variables such as population, income, competition from other sports teams, basketball fanaticism, and corporate depth. Team characteristics contain variables such as prices, winning percentage, and arena quality. The relationship that results from revenue potential is an input into the location relationship. This creates a hierarchical, twoequation system. Owner preferences are excluded from the models because they are based on where an owner would like to locate a team and determining this is above and beyond the scope of economic and political factors. In addition, franchises that are owned by a group or a corporation would have divergent owner preferences.

Similarly, there are difficulties in trying to model political support. For one thing, the political support for constructing an NBA arena in a city without an NBA team might not be revealed in any data available if the issue has not previously arisen. Information on political support for other major professional sports teams might be a useful, comparable variable, but many of these cities do not have any other major professional sports teams. In addition, if a city has already spent a large sum of public money to build a baseball stadium, it is often unclear whether it would be more or less likely to finance an NBA arena with public funds.

Another avenue in modeling potential political support is to note whether political leaders account for the public's preferences when spending public money, or if the public votes directly on the issue. If the public votes on the issue, then a measure of the public's preferences towards basketball might be informative. An explanatory variable of the location model, basketball fanaticism, might capture the public's likely support for publicly financing an arena. In fact, there is a correlation of - .23 between the existing degree of public support for the current arena (in those cities with an NBA team) and the basketball fanaticism ranking (which is defined as higher means = less fanatical, and it is significant at the 5\% level). ${ }^{10}$ Further, cities with higher populations (another of the explanatory variables in the 
model) are more likely to publicly fund an arena. ${ }^{11}$ Therefore, basketball fanaticism and population partially capture the degree of political support that an owner might expect to receive in each potential location.

In summary, the theoretical model is a two-equation system measuring whether a city is a good or poor candidate for an NBA team. A testable assumption is that NBA cities that maintain a team over a long period of time have factors in common. For example, the empirical analysis will determine the importance of population as a common factor that successful NBA teams share.

The two-equation system representing the model is as follows:

$$
\begin{aligned}
& Y_{1}=\alpha Y_{2}+\beta_{1} X_{1}+\mu_{1} \\
& Y_{2}=\beta_{2} X_{2}+\mu_{2}
\end{aligned}
$$

where $Y_{1}$ is a binary variable, $X_{1}$ and $X_{2}$ are vectors of independent variables, $\mu_{1}$ and $\mu_{2}$ are error terms, $\alpha$ and $\beta_{i}(i=1,2)$ are vectors of parameters to be estimated, and $Y_{2}$ is a continuous variable. Equation 2 is a revenue equation, is based on the triangular hierarchical structure, and feeds into Equation 1, the location equation. $Y_{1}$ takes a value of 1 if the city contains an NBA team, and 0, otherwise. The error terms, $\mu_{1}$ and $\mu_{2}$, are not uncorrelated because $Y_{2}$ is correlated with $\mu_{2}$, and, given that $Y_{2}$ is part of equation $1, \mu_{2}$ is correlated with $\mu_{1}$.

Equation 1 models cities that currently have NBA franchises based on $X_{1}$ (market characteristics) and $Y_{2}$ (a forecast of potential revenue for an NBA team in that location). Equation 2 is a forecast equation that is an input into Equation 1. It is explained by factors in $X_{2}$, such as market characteristics and team characteristics, that affect the revenue of NBA teams.

\section{Data}

The cross-sectional data for Equation 1 of the location model consists of 48 observations from 1999 (unless otherwise specified): 25 are for cities with NBA teams, and 23 are for cities without NBA teams that are potentially the most eligible cities for league expansion or team relocation. ${ }^{12}$ There are 12 potential explanatory variables, some of which are correlated (e.g., 1995 metropolitan statiscal area [MSA] population and $2000 \mathrm{MSA}$ population). ${ }^{13}$ Each observation represents information for the year 1999 (except where specified).

The dependent variable in Equation 1, $Y_{1}$, is an indicator or dummy variable that distinguishes a city with an NBA team (or two) from a prospective NBA city without a team for the 1999 season.

In developing a forecasting model for possible locations for NBA teams, it is imperative to include the population of the market for each team. Five population variables are examined: 1990 city population, 1999 city population, MSA population for the years 1995 and 2000, and the MSA population growth over that period. ${ }^{14}$ It is likely that an NBA team draws not only from the city in which it is located but also from the surrounding towns and communities. Therefore, the MSA population is expected to provide the best relative forecast of the population 


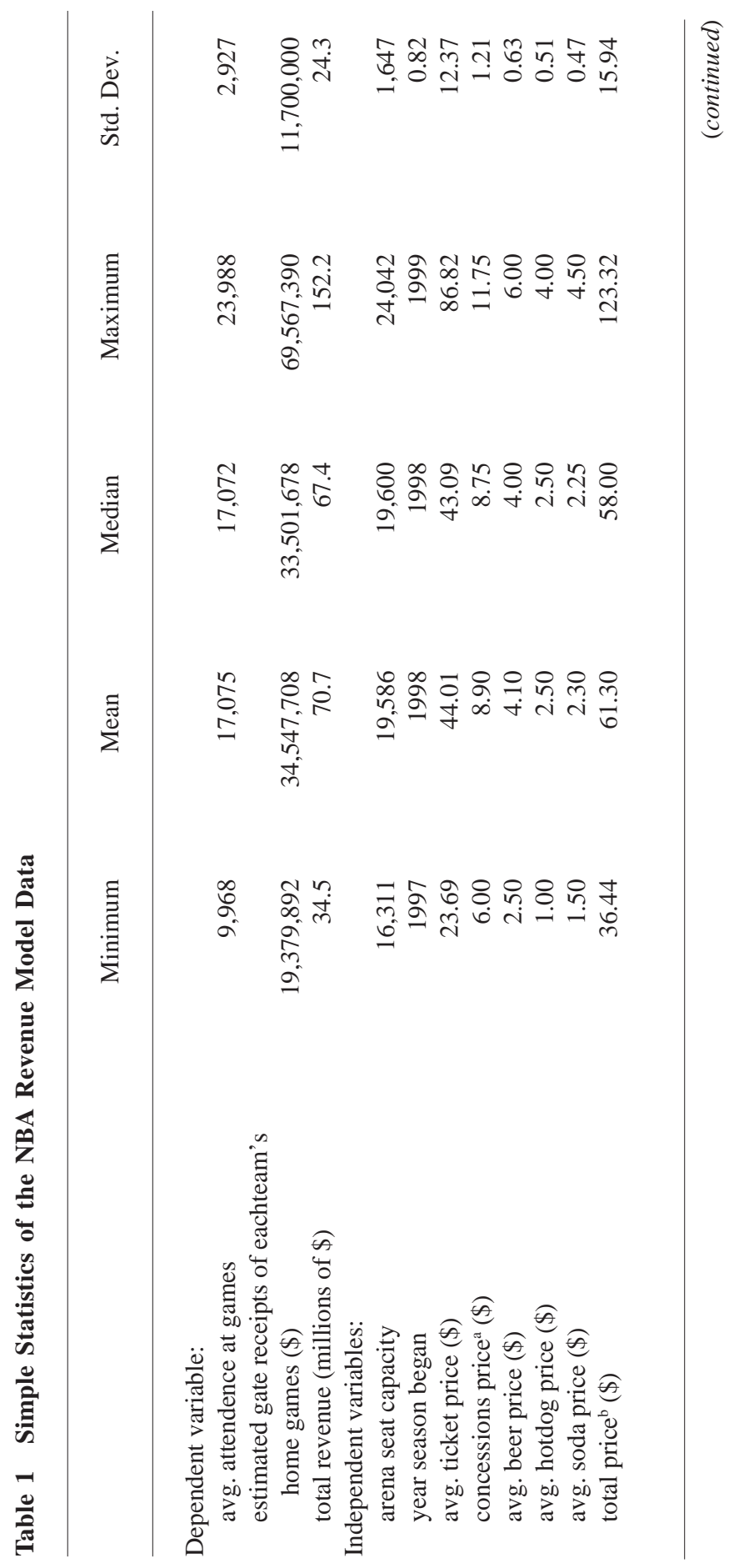




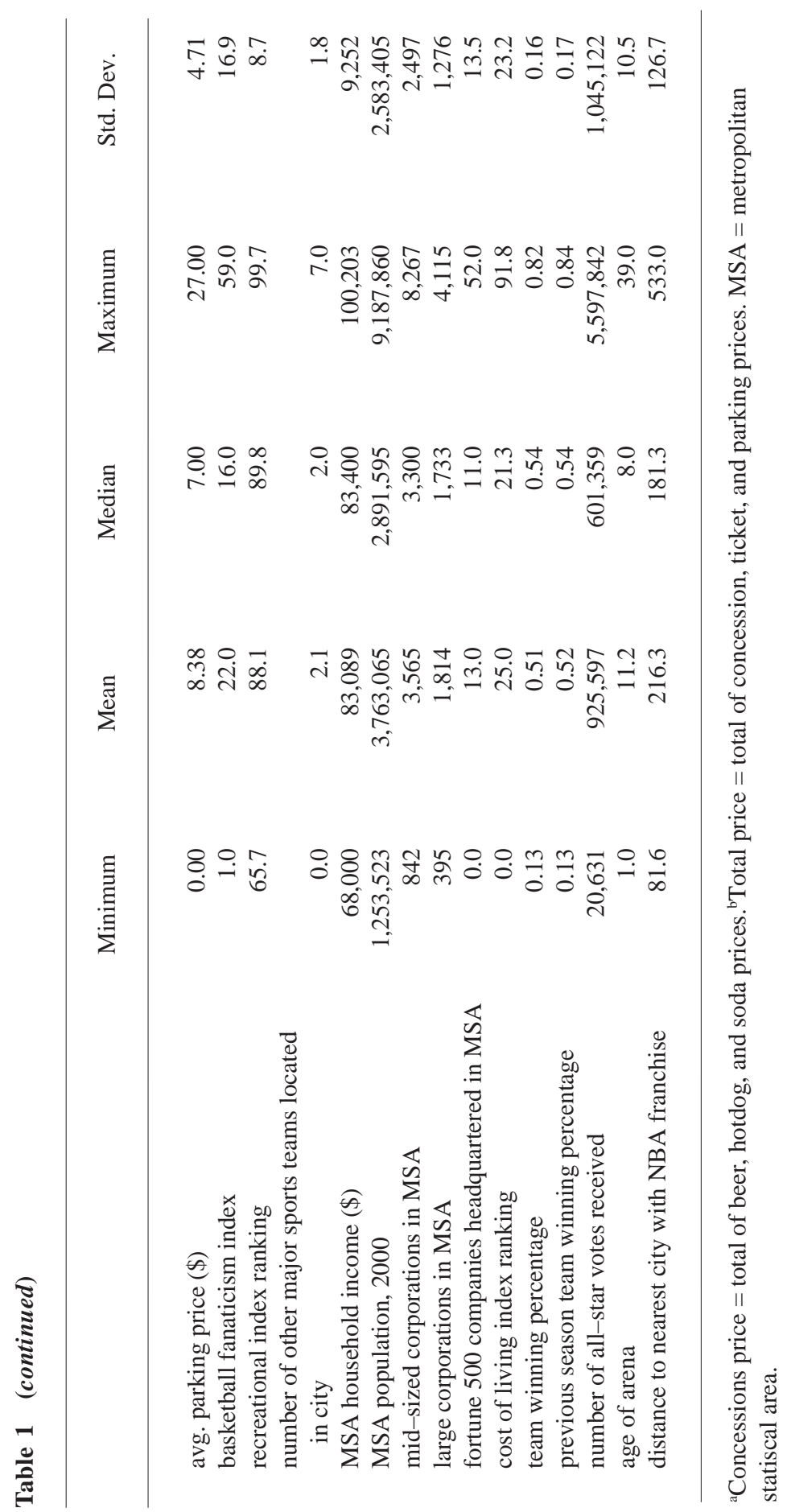


variables. It is expected that the effect of population on whether a city has or attains an NBA team will be positive. A summary of the data is provided in Table 1.

The growth of a community could play a role in whether an NBA team chooses to locate there, especially if annual growth is significant and consistent. The growth variable is the change in MSA population during the past 5 years. The expected effect is that a higher population growth rate will increase the probability of an NBA team choosing to locate in a particular area. Alternatively, a city that has a significant decline in population might decrease the probability of an NBA team choosing to locate in there.

Typical household income and average pay per worker of the MSA are also included as potential determining factors of NBA franchise location. ${ }^{15}$ Other studies have found income to be a significant factor in determining attendance at sporting events. ${ }^{16}$ As for location of sports teams, Bruggink and Zamparelli (1999) found that an increase in average household income by $\$ 1,000$ increased the probability of the city having a MLB team by $8 \%$. The expected effect is that a higher typical household income in an MSA will increase the probability of an NBA team choosing that location.

Similarly, a measure of the relative cost of living in these metropolitan areas is considered in order to obtain a reasonable measure of household disposable income. The cost of living index takes into consideration nine items that collectively represent more than $60 \%$ of the typical household budget, which varies widely among regions. ${ }^{17}$ The annual costs for these items were ranked from lowest to highest and then scored such that 100.00 represents the least expensive, 50.00 indicates the median, and 0.00 ranks as the most expensive city. The theory here is that regions with higher disposable income might choose to allocate a higher percentage of their budget towards recreational and leisure activities, such as attending an NBA game.

The success of sports teams in the modern era is largely dependent on corporate support via the purchase of luxury suites, club seats, sponsorship (including naming rights), and other premium services. The locational analysis includes a measure of corporate supply by using the number of Fortune 500 companies that are headquartered in a relevant city. ${ }^{18}$ Although not a perfect measure of corporate supply, it is expected that large corporations might want to entertain clients or employees in the luxury suites of a professional sports franchise located in the city in which they are headquartered. Also included are two measures of the number of companies that are considered to be large enough to be interested in premium services, such as luxury seats, and profitable enough to be able to afford such services. ${ }^{19}$

As in any spatial model of competition, the distance between competitors can affect the success of a business. The distance in miles to the nearest city with an NBA team is used as a measure of spatial competition. All else equal, it is expected that franchises that are located far distances from other franchises have a higher likelihood of success. ${ }^{20}$

Competitors to a sports franchise would be any other major professional sports teams located in the same area. For instance, a sports fan might choose to 
attend a hockey game instead of a basketball game. If there was not a hockey team nearby, however, the fan might choose the basketball game for lack of other sporting alternatives. Therefore, the hypothesis is that the fewer major professional sports teams there are in a given area, the higher the likelihood will be of success for an NBA team. The number of teams in the other major professional sports leagues (NHL, NFL, and MLB) is used as a proxy for sports-entertainment competition. Bruggink and Zamparelli (1999) found that the number of other sports teams had a positive effect on the location of MLB teams, stating that "the placement of other professional teams establishes the city as "major league.",21

Similarly, an index of the recreational assets available in an MSA is also included. This is determined by a factor analysis assessed on thirteen criteria to rate an MSA's supply of recreation assets. ${ }^{22}$ These totals are ranked from greatest (100.0) to lowest (0.0) supply of recreational assets. The hypothesis here is that fewer recreational assets (lower index score) will result in fewer recreational alternatives to attending an NBA game.

Recently, Scarborough Sports Marketing created an index of basketball fanaticism based on their survey of U.S. markets. This index is a measure of the importance of basketball to local residents. For instance, some regions, such as Indiana, North Carolina, Louisville, and New York City, are known as basketball 'hotbeds.' The index is used as a measure of consumer demand for NBA games and ranges from 1 for the most fanatical city to 63 for the city with the least fanaticism.

Equation 2 uses a panel data set consisting of nineteen variables for each team in the NBA (except the two Canadian teams) over the years 1997-1999. ${ }^{23}$ There are three dependent variables: attendance, an estimate of gate receipts, and total team revenue. The focus of this part of the research is to create a forecasting model for financial success in the NBA with the proxy for success being total game attendance, gate receipts, or total revenue. Unlike the NFL, total revenues in the NBA are highly correlated with gate receipts because there is not a significant amount of revenue sharing in the NBA. ${ }^{24}$

Average attendance is being used instead of total attendance because of the lockout during the 1999 season that caused the cancellation of approximately 32 games out of an 82-game season, including the All-Star Game. The playoffs, however were not cancelled. High attendance represents one of the goals of a sports organization. See Table 2 for a summary of the data used for Equation 2.

High gate receipts are another goal of sports organizations. Gate receipts also help account for capacity constraints, whereas attendance does not. For instance, smaller arenas can charge higher prices if the supply of seats is less than the demand, mitigating part of the capacity constraint issue. Ticket prices vary significantly across teams, and, by using only attendance, this price information would be lost. Gate receipts are estimated using actual attendance and average ticket price for all 3 years. Actual gate receipts are proprietary information, so obtaining exact information is difficult. Therefore, an estimate was used. For the one season of actual gate receipts for NBA teams that is available, the correlation 


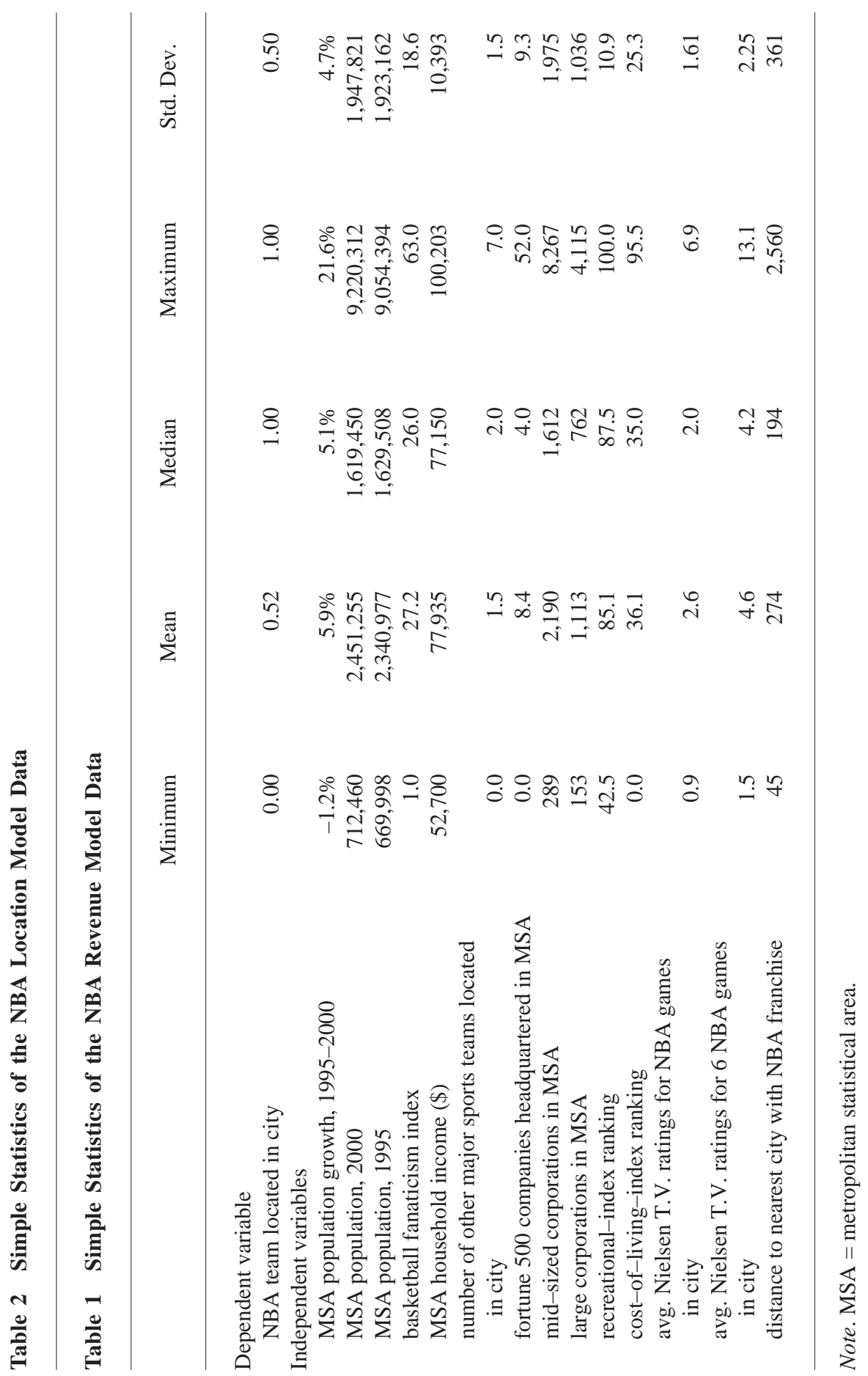


between the estimate and the actual is $.94 .^{25}$ This analysis uses an estimate based on attendance and average ticket price.

The third measure of revenue is total team revenue as reported by Forbes magazine. Other localized revenue sources not included in gate receipts such as media, sponsorship, concessions, and parking are included in this figure.

The independent variables used to predict financial success or to measure attendance demand are prices, team winning percentage, a measure of the quantity of star players, the age of the venue, the year of the season, basketball fanaticism, household income, number of other professional sports teams located in the MSA, 2000 MSA population, recreational and cost-of-living indices, number of Fortune 500 companies headquartered in MSA, the number of midsized and large corporations in MSA, and distance to nearest NBA city.

There is also a vector of prices that fans pay to attend sporting events. These include the ticket price, the price of a 12-oz beer, the price of a hot dog, the price of a 12-oz soda, and the price of parking. ${ }^{26}$ The first law of demand predicts that higher prices will lead to lower levels of demand, ceteris paribus. Ticket prices average $\$ 44$ for the sample, with a low of $\$ 24$ and a high of $\$ 87$.

Winning percentage is expected to be an important proxy for the quality of the home team. The winning percentage in the year each season began, for 1997 through 1999, was used. ${ }^{27}$ Many studies have found winning to be an important determinant of attendance demand. ${ }^{28}$ As expected, the average winning percentage is near .500 (at .514), with the minimum at .134 and the maximum at $.817 .^{29}$

Lagged winning percentage is also expected to affect demand because the previous season's performance affects season ticket sales and the appeal of earlyseason games. For instance, Rascher (1999) shows that, in baseball, an extra win by the home team in the previous season increases per-game attendance by about 450 fans for the first half of the season, but by the second half of the season, the increase declines in magnitude to 150 fans per game (signfigance declines, as well, with the $t$ statistic dropping from 7.64 to 3.02).

Relative to other major professional sports, the NBA markets its product by focusing on the individual talent of the players more so than the quality of each team. It is expected that the star power of the players on a team will affect the demand for games above and beyond their skill in producing wins. The analysis uses the number of All-Star votes that each team received as a proxy for the individual star power of each team.

Sports teams in the U.S. have been on a facility construction spree in the last decade. The older domes built in the late 1960s and early 1970s have given way to newer, higher quality, entertainment-oriented facilities. These facilities increase the revenue streams for NBA and NHL teams by as much as $50 \%$ because they offer better amenities including premium seating, parking, food, drink, and nongame entertainment. In MLB, a new stadium can generate more than \$40 million in new revenue annually. ${ }^{30}$ The analysis uses the age of the sports venue as a proxy for the quality of the experience that the fan receives that is unrelated to the game. The remaining variables were described earlier. 


\section{Analysis and Results}

The location model creates a forecast of the best cities for NBA expansion or relocation based on economic factors that exist in current NBA cities. The dependent variable, whether the city has an NBA team, is an indicator variable. The model is a two-equation system with a binary dependent variable and a continuous endogenous variable. The type of triangular system described in the section on the theoretical model requires a two-stage probit least squares (2SPLS) estimation technique.

The first stage is the estimation of Equation 2, the revenue equation. Typically, OLS $\square$ estimation would be unbiased and efficient, but there are a few econometric issues that prevent straight OLS from working. First, the revenue equation is estimated using data for 27 teams over 3 years. The error structure exhibits cluster correlation. For each team, the error term for 3 years is auto-correlated. Even though there is not correlation across teams, there is correlation of the errors within each team. The effect of cluster correlation is to inflate $t$ statistics. In this case, the $t$ statistics are about $12 \%$ higher when not accounting for the cluster correlation problem. The solution involves estimating robust errors by analyzing a cluster variable in the model itself.

The second estimation problem is that one of the dependent variables, attendance, is censored because of the capacity constraint of the size of an arena. True demand might be larger than actual attendance, but the size of the arena prevents the full demand from being satisfied. Interval regression offers a solution in the tradition of Tobit.

In calculating the correlation between each of the variables, income and population, as expected, are correlated-people in larger cities have higher incomes. Another multicollinearity issue is among population, the number of corporate headquarters, and the number of non-NBA-sports teams. The smallest bivariate correlation among these variables is .73. Although it is not surprising that corporations and sports teams locate in large population centers, the interpretation of the individual effects of these factors on NBA team location could be inefficient, but not biased, if included simultaneously in econometric analysis. Because the goal in this step of the analysis is not to interpret individual effects but to create an endogenous variable to be used in the next step, these variables were included in the analysis.

Sensitivity analyses showed that there was no omitted variable bias. Evidence of heteroscedasticity was accounted for using White's corrected errors. Loglinear models were estimated, but the levels models had superior fit. Log-linear models are often used in demand estimation, but only because the elasticities are easy to calculate. In this case that reason is not compelling enough to use loglinear models. Table 3 shows the results of the revenue and attendance equations estimation.

Overall, the attendance model is extremely statistically significant with a Wald $\chi^{2}$ statistic of 74.14. Both the gate receipts and total-revenue models have $R^{2}$ values greater than 0.53 and $F$ values that are significant at the $1 \%$ level. Each of 
Table 3 Attendance and Revenue Regression Results

\begin{tabular}{|c|c|c|c|}
\hline Model & $\begin{array}{l}\text { Attendance } \\
\quad(S D)\end{array}$ & $\begin{array}{l}\text { Gate receipts } \\
\qquad(S D)\end{array}$ & $\begin{array}{r}\text { Total revenue } \\
\text { in millions }(S D)\end{array}$ \\
\hline Adjusted $\mathrm{R}^{2}$ & - & 0.55 & 0.53 \\
\hline F-value or Wald Chi ${ }^{2}$ & $74.14 * * *$ & $13.42 * * *$ & $7.86 * * *$ \\
\hline Number of observations & 81 & 81 & 81 \\
\hline \multicolumn{4}{|l|}{ Independent variables } \\
\hline constant & $\begin{array}{c}1447.55 \\
(0.19)\end{array}$ & $\begin{array}{c}-39,100,000 * * \\
(-2.14)\end{array}$ & $\begin{array}{l}-24.4 \\
(-0.56)\end{array}$ \\
\hline basketball fanaticism index & $\begin{array}{c}-91.06 * * * \\
(-3.28)\end{array}$ & $\begin{array}{c}-319,263 * * * \\
(-4.38)\end{array}$ & $\begin{array}{l}-0.35 \\
(-1.62)\end{array}$ \\
\hline number of other major sports & 405.40 & $1,209,033$ & 2.79 \\
\hline teams located in city & $(1.12)$ & $(0.82)$ & $(0.70)$ \\
\hline population of local MSA & $\begin{array}{l}0.0000485 \\
\quad(0.10)\end{array}$ & $\begin{array}{c}1.71 \\
(1.39)\end{array}$ & $\begin{array}{l}0.0000031 \\
(1.09)\end{array}$ \\
\hline index of recreation opportunities & $\begin{array}{l}27.09 \\
(0.75)\end{array}$ & $\begin{array}{c}118,218 \\
(1.15)\end{array}$ & $\begin{array}{c}0.26 \\
(1.06)\end{array}$ \\
\hline MSA household income & $\begin{array}{c}0.1490 * \\
(1.67)\end{array}$ & $\begin{array}{c}680.2 * * * \\
(3.26)\end{array}$ & $\begin{array}{c}0.00044 \\
(0.95)\end{array}$ \\
\hline $\begin{array}{l}\text { number of midsized companies } \\
\text { in MSA }\end{array}$ & $\begin{array}{l}-0.924 \\
(-0.74)\end{array}$ & $\begin{array}{l}-4208^{*} \\
(-1.76)\end{array}$ & $\begin{array}{c}0.00034 \\
(0.06)\end{array}$ \\
\hline $\begin{array}{l}\text { current season winning } \\
\text { percentage }\end{array}$ & $\begin{array}{c}1451.47 \\
(0.52)\end{array}$ & $\begin{array}{l}9,033,650 \\
(0.87)\end{array}$ & $\begin{array}{c}36.53 * \\
(1.72)\end{array}$ \\
\hline $\begin{array}{l}\text { previous season team winning } \\
\text { percentage }\end{array}$ & $\begin{array}{c}8136.83 * * * \\
(4.02)\end{array}$ & $\begin{array}{c}13,500,00 * * * \\
(2.82)\end{array}$ & $\begin{array}{c}22.96 * * \\
(1.97)\end{array}$ \\
\hline age of arena & $\begin{array}{l}-73.06 \\
(-1.37)\end{array}$ & $\begin{array}{c}-235,793^{*} \\
(-1.65)\end{array}$ & $\begin{array}{c}-0.52 \\
(-1.62)\end{array}$ \\
\hline
\end{tabular}

Note. Significance: $*=10 \%$ level $; * *=5 \%$ level $; * * *=1 \%$ level. MSA $=$ metropolitan statistical area.

the Stage-1 models is statistically significant and provides suitable endogenous variables for Stage 2. Basketball fanaticism, household income, previous season's winning percentage, and age of the arena are consistently statistically significant with the expected signs. ${ }^{31}$ Interpreting the marginal impacts of a few of the variables that do not suffer from multicollinearity, a 5\% increase in household income is associated with an $8 \%$ increase in gate receipts. An $10 \%$ increase in games won (e.g., from 0.500 to 0.600 - eight more wins) is associated with a rise in gate receipts of $4 \%$, or $\$ 1.35$ million. The aging of a stadium is associated with lower gate receipts, about $\$ 235,000$ per year.

Table 4 shows the forecasts of attendance, gate receipts, and total revenue for each NBA and non-NBA city, sorted by decreasing gate receipts. ${ }^{32}$ Gate receipts range from a high of $\$ 84$ million in Chicago, down to $\$ 32$ million in $\mathrm{El}$ 
Table 4 Forecasted Attendance, Gate Receipts, and Total Revenue

\begin{tabular}{|c|c|c|c|}
\hline $\begin{array}{l}\text { City/Team } \\
\text { (sorted by gate receipts) }\end{array}$ & $\begin{array}{l}\text { Forecasted } \\
\text { attendance }\end{array}$ & $\begin{array}{c}\text { Forecasted } \\
\text { gate receipts }(\$)\end{array}$ & $\begin{array}{c}\text { Forecasted } \\
\text { total revenue }(\$)\end{array}$ \\
\hline Chicago Bulls & 20,108 & $45,283,019$ & $103,944,723$ \\
\hline New Jersey Nets & 19,667 & $44,609,289$ & $103,666,295$ \\
\hline New York Knicks & 18,717 & $41,543,980$ & $96,906,295$ \\
\hline Washington Wizards & 19,704 & $41,358,306$ & $83,281,956$ \\
\hline Los Angeles Clippers & 17,899 & $38,422,655$ & $97,575,067$ \\
\hline Los Angeles Lakers & 17,899 & $38,422,655$ & $97,575,067$ \\
\hline Seattle SuperSonics & 19,757 & $38,312,641$ & $71,904,303$ \\
\hline Detroit Pistons & 18,249 & $34,583,135$ & $77,497,291$ \\
\hline Houston Rockets & 18,325 & $34,298,557$ & $69,692,269$ \\
\hline Boston Celtics & 18,218 & $33,924,509$ & $68,763,022$ \\
\hline Indiana Pacers & 19,235 & $32,993,512$ & $66,299,117$ \\
\hline Philadelphia 76ers & 17,729 & $32,781,592$ & $75,895,337$ \\
\hline Portland Trail Blazers & 18,715 & $32,330,039$ & $64,190,119$ \\
\hline Memphis & 18,796 & $31,596,200$ & $59,847,117$ \\
\hline Utah Jazz & 18,622 & $31,209,019$ & $62,109,120$ \\
\hline Hartford & 18,134 & $30,943,166$ & $56,251,917$ \\
\hline Phoenix Suns & 18,286 & $30,498,141$ & $72,479,118$ \\
\hline Minnesota Timberwolves & 17,526 & $30,384,199$ & $67,701,633$ \\
\hline Miami Heat & 18,315 & $29,977,964$ & $67,583,986$ \\
\hline Baltimore & 17,560 & $29,429,689$ & $64,518,291$ \\
\hline Louisville & 18,311 & $28,911,371$ & $59,396,878$ \\
\hline San Diego & 17,372 & $28,460,087$ & $66,524,446$ \\
\hline Las Vegas & 17,545 & $27,242,661$ & $59,699,671$ \\
\hline Nashville & 17,528 & $26,882,101$ & $58,132,275$ \\
\hline Milwaukee Bucks & 16,978 & $26,290,903$ & $58,624,142$ \\
\hline Sacramento Kings & 17,138 & $26,101,881$ & $52,459,725$ \\
\hline Golden State Warriors & 15,762 & $26,011,957$ & $63,966,882$ \\
\hline Honolulu & 16,467 & $25,830,914$ & $50,552,504$ \\
\hline San Antonio Spurs & 17,354 & $25,604,283$ & $54,161,323$ \\
\hline \multicolumn{4}{|l|}{ Norfolk, Virginia Beach, } \\
\hline Newport News & 17,058 & $24,720,174$ & $59,816,386$ \\
\hline Dallas Mavericks & 15,907 & $24,685,943$ & $60,500,450$ \\
\hline Charlotte Hornets & 16,516 & $23,644,230$ & $51,580,247$ \\
\hline St. Louis & 16,074 & $23,606,227$ & $62,257,248$ \\
\hline Atlanta Hawks & 15,625 & $23,464,312$ & $62,783,478$ \\
\hline Orlando Magic & 16,506 & $23,263,533$ & $55,287,320$ \\
\hline New Orleans & 16,314 & $22,026,250$ & $59,897,920$ \\
\hline Jacksonville & 16,085 & $21,331,308$ & $54,111,519$ \\
\hline Cincinnati & 15,644 & $20,361,607$ & $53,771,644$ \\
\hline Cleveland Cavaliers & 15,119 & $20,272,483$ & $56,035,523$ \\
\hline
\end{tabular}


Table 4 (continued)

\begin{tabular}{lccc}
\hline $\begin{array}{l}\text { City/Team } \\
\text { (sorted by gate receipts) }\end{array}$ & $\begin{array}{c}\text { Forecasted } \\
\text { attendance }\end{array}$ & $\begin{array}{c}\text { Forecasted } \\
\text { gate receipts }(\$)\end{array}$ & $\begin{array}{c}\text { Forecasted } \\
\text { total revenue }(\$)\end{array}$ \\
\hline Austin-San Marcos & 15,931 & $19,766,609$ & $49,390,583$ \\
Denver Nuggets & 14,939 & $19,541,896$ & $51,326,220$ \\
Kansas City & 15,280 & $19,503,955$ & $54,329,534$ \\
Albuquerque & 15,394 & $17,362,572$ & $45,547,891$ \\
Columbus & 13,879 & $13,684,159$ & $45,976,470$ \\
Pittsburgh & 13,357 & $12,543,029$ & $48,788,601$ \\
Omaha & 13,553 & $12,345,181$ & $39,255,986$ \\
Buffalo-N. Falls & 13,659 & $11,974,656$ & $46,414,481$ \\
Oklahoma City & 11,432 & $11,114,854$ & $33,726,430$ \\
Tucson & 11,071 & $10,608,078$ & $31,618,100$ \\
El Paso & 9,311 & $10,178,875$ & $19,506,282$ \\
& & & \\
\hline
\end{tabular}

Note. Bolded cities are those without an NBA team in 1999.

Paso, TX. Based on these Stage-1 results (revenues), the best cities for expansion or relocation are Memphis, Hartford, Baltimore, Louisville, San Diego, Las Vegas, and Nashville.

The second stage of the 2SPLS involves the estimation of Equation 1 with the estimated dependent variable from Equation 2 as an endogenous variable in the model. Again, the attendance, gate receipts, and total revenue estimates from Table 3 are regressors in the estimation of Equation 2. A number of sensitivity tests were performed on the model before final selection occurred. Scatter plots and the Cook-Weisberg test show that heteroscedasticity is an issue with the data. White's corrected errors are used to avoid inflated $t$ statistics from heteroscedasticity. There appears to be one or more omitted variables based on the results of the Ramsey RESET test.

Table 5 shows the results of the probit analysis. Overall, the models are significant at the $5 \%$ or better level. Interpretation of the marginal impacts shows that a $10 \%$ increase in attendance, gate receipts, or total revenue is associated with an $11 \%, 10 \%$, and $17 \%$ increase in the probability that a city is suitable for an NBA team, respectively.

\section{Conclusion and Discussion}

The forecasts for which cities are "best" for NBA expansion or relocation are shown in Table 6. Louisville and San Diego lead the list of potential candidates. This model examines the underlying economic structure of the cities in order to create forecasts for expansion or relocation of NBA teams. Models of this type could be used for many other sports and in other regions and countries. 
Table 5 Two-Stage Probit Least Squares Results

\begin{tabular}{|c|c|c|c|}
\hline Model & $\begin{array}{l}\text { NBA indicator } \\
\text { variable }(S D)\end{array}$ & $\begin{array}{l}\text { NBA indicator } \\
\text { variable }(S D)\end{array}$ & $\begin{array}{l}\text { NBA indicator } \\
\text { variable }(S D)\end{array}$ \\
\hline Wald Chi-Square & $5.84 * *$ & $12.66 * * *$ & $9.86 * * *$ \\
\hline Number of Observations & 45 & 45 & 45 \\
\hline \multicolumn{4}{|l|}{ Independent Variables } \\
\hline constant & $\begin{array}{l}-3.30 * * \\
(-2.21)\end{array}$ & $\begin{array}{l}-3.16^{* * *} \\
(-3.08)\end{array}$ & $\begin{array}{l}-5.95^{* * *} \\
(-2.98)\end{array}$ \\
\hline attendance from stage one & $\begin{array}{c}2.14 \mathrm{e}-4 * * * \\
(2.42)\end{array}$ & $\begin{array}{c}1.15 \mathrm{e}-7 * * * \\
-\end{array}$ & - \\
\hline gate receipts from stage one & - & $(3.56)$ & $0.0855^{* * *}$ \\
\hline total revenue from stage one & - & - & $(3.14)$ \\
\hline
\end{tabular}

Note. Significance: $*=10 \%$ level; $* *=5 \%$ level; $* * *=1 \%$ level.

Before the 2001-2002 season, the Vancouver Grizzlies of the NBA had to make a location decision. The team decided to move out of Canada and created a short list of possible locations that they believed could sustainably and successfully support the franchise. San Diego, Las Vegas, New Orleans, Memphis, and Louisville were on the list. The city of San Diego showed no interest in the Grizzlies because, at the time, the city was embroiled in a dispute over a half-built, publicly financed baseball stadium. The NBA ruled out the city of Las Vegas because of its ties to gambling. St. Louis had been a contender the year before the sale, but after the failed purchase of the team by St. Louis Blues (NHL) owner, Bill Laurie, he declared he would not open the Savvis Center to a an NBA team of which he was not the owner. The three final locations were quickly narrowed to two, because New Orleans was unable to generate an offer that was suitable to the Grizzlies. The decision between Memphis and Louisville was tipped in favor of Memphis when Federal Express (FedEx), whose headquarters are in Memphis, made a naming rights offer and equity purchase of the team. ${ }^{33}$ The results here support the location decision made by the Grizzlies.

More recently, the Hornets considered Louisville, Norfolk, VA, and New Orleans for their relocation out of Charlotte before agreeing to terms with New Orleans. Based on the findings in this study, the Hornets might have been better off moving to Louisville. This is supported by the fact that attendance last season in New Orleans was below expectations.

Changes in the revenue-generating capability of sports facilities are among the most important factors that have improved the profitability of sports-team franchises recently. All four of the major professional sports leagues have recently seen an increase in the variance of team valuations because the team owners retain 
Table 6 Forecast Results for Location Model Predicting Probable NBA Cities

\begin{tabular}{|c|c|c|c|}
\hline $\begin{array}{l}\text { City/Team } \\
\text { (sorted by gate receipts) }\end{array}$ & $\begin{array}{l}\text { Forecasted } \\
\text { probability } \\
\text { (attendance) }\end{array}$ & $\begin{array}{c}\text { Forecasted } \\
\text { probability } \\
\text { (gate receipts) }\end{array}$ & $\begin{array}{c}\text { Forecasted } \\
\text { probability } \\
\text { (total revenue) }\end{array}$ \\
\hline Atlanta Hawks & 1.000 & 1.000 & 1.000 \\
\hline Boston Celtics & 1.000 & 1.000 & 1.000 \\
\hline Chicago Bulls & 1.000 & 1.000 & 1.000 \\
\hline Dallas Mavericks & 1.000 & 1.000 & 1.000 \\
\hline Detroit Pistons & 1.000 & 1.000 & 1.000 \\
\hline Houston Rockets & 1.000 & 1.000 & 1.000 \\
\hline Los Angeles Lakers & 1.000 & 1.000 & 1.000 \\
\hline Los Angeles Clippers & 1.000 & 1.000 & 1.000 \\
\hline Minnesota Timberwolves & 1.000 & 1.000 & 1.000 \\
\hline New York Knicks & 1.000 & 1.000 & 1.000 \\
\hline New Jersey Nets & 1.000 & 1.000 & 1.000 \\
\hline Golden State Warriors & 1.000 & 1.000 & 1.000 \\
\hline Philadelphia 76ers & 1.000 & 1.000 & 1.000 \\
\hline Washington Wizards & 1.000 & 1.000 & 1.000 \\
\hline Portland Trail Blazers & 1.000 & 1.000 & 1.000 \\
\hline Seattle SuperSonics & 0.997 & 0.998 & 0.990 \\
\hline Phoenix Suns & 0.937 & 0.989 & 0.947 \\
\hline Utah Jazz & 0.963 & 0.962 & 0.912 \\
\hline Charlotte Hornets & 0.919 & 0.954 & 0.896 \\
\hline Indiana Pacers & 0.873 & 0.953 & 0.901 \\
\hline Orlando Magic & 0.816 & 0.862 & 0.817 \\
\hline Louisville & 0.740 & 0.743 & 0.751 \\
\hline Milwaukee Bucks & 0.501 & 0.709 & 0.520 \\
\hline Denver Nuggets & 0.675 & 0.707 & 0.715 \\
\hline San Antonio Spurs & 0.404 & 0.703 & 0.549 \\
\hline San Diego & 0.696 & 0.677 & 0.658 \\
\hline Miami Heat & 0.675 & 0.585 & 0.615 \\
\hline Las Vegas & 0.416 & 0.345 & 0.442 \\
\hline Baltimore & 0.252 & 0.288 & 0.256 \\
\hline St Louis & 0.271 & 0.279 & 0.299 \\
\hline Cleveland Cavaliers & 0.351 & 0.262 & 0.323 \\
\hline \multicolumn{4}{|l|}{ Norfolk, Virginia Beach, } \\
\hline Newport News & 0.220 & 0.255 & 0.352 \\
\hline Memphis & 0.486 & 0.241 & 0.331 \\
\hline Pittsburgh & 0.333 & 0.163 & 0.328 \\
\hline Hartford & 0.209 & 0.155 & 0.164 \\
\hline Nashville & 0.125 & 0.115 & 0.152 \\
\hline Sacramento Kings & 0.130 & 0.107 & 0.087 \\
\hline
\end{tabular}


Table 6 (continued)

\begin{tabular}{lccc}
\hline $\begin{array}{l}\text { City/Team } \\
\text { (sorted by gate receipts) }\end{array}$ & $\begin{array}{l}\text { Forecasted } \\
\text { probability } \\
\text { (attendance) }\end{array}$ & $\begin{array}{c}\text { Forecasted } \\
\text { probability } \\
\text { (gate receipts) }\end{array}$ & $\begin{array}{c}\text { Forecasted } \\
\text { probability } \\
\text { (total revenue) }\end{array}$ \\
\hline Austin - San Marcos & 0.073 & 0.055 & 0.118 \\
Kansas City & 0.017 & 0.015 & 0.036 \\
Cincinnati & 0.003 & 0.001 & 0.004 \\
New Orleans & 0.002 & 0.000 & 0.004 \\
Columbus & 0.002 & 0.000 & 0.004 \\
Jacksonville & 0.000 & 0.000 & 0.000 \\
Albuquerque & 0.000 & 0.000 & 0.000 \\
Buffalo - N.Falls & 0.000 & 0.000 & 0.000 \\
\hline
\end{tabular}

Note. Bolded cities are those without an NBA team in 1999.

much of facility revenues. Although the size and magnitude of a team's market is important in determining its revenue-generating ability in the league, facility economics has quickly caught up with market size in determining financial success, as evidenced by the recent franchise moves and the awarding of a new NFL franchise to Houston over Los Angeles.

The major determinants of the profitability of any major professional sports franchise are the type of lease agreement it has and the quality of its stadium. Hence, an important aspect of the location decision is not only the underlying economics of the market but also the actual lease agreement offered to a team by each city. In other words, if the market economics are better in a larger city, models of this sort can help determine how much better a lease agreement has to be from a smaller city in order to convince an owner to move to the smaller city. ${ }^{34}$

If an expansion team were considering a relatively larger market such as Kansas City (population of 1.8 million), for example, versus a smaller market such as Buffalo (population of 1.2 million), the model forecasts that a Kansas City team would generate about $\$ 8$ million more per year in total revenue (about 17\% more) than would a team in Buffalo. In order for a team to move to Buffalo, the lease agreement would have to include at least $\$ 8$ million more per year in expected revenue for the team. For instance, the combination of lower rent, property tax, sales tax, percentages of parking, concessions, etc. that the team keeps would have to add up to at least $\$ 8$ million more than the lease in Kansas City offered.

In a real example, in choosing New Orleans over Louisville, the Hornets assessed expected attendance, gate receipts, and total revenues. According to the findings here, expected total revenues were about the same, but attendance and gate receipts were forecasted to be higher in Louisville than in New Orleans. 
Presumably, the lease agreement in New Orleans accounted for the difference in forecasted gate receipts between the two possible locations.

In choosing Memphis over New Orleans, Louisville, St. Louis, Las Vegas, and San Diego, the Grizzlies chose the market with the highest expected attendance and gate receipts but not the highest total revenue. As described earlier in this article, however, San Diego was not in a position to offer to build a new facility and the owner of the Savvis Center in St. Louis was not interested in having an NBA team in the facility unless he owned it.

By using a hierarchical, two-equation system involving the underlying economic factors that are deterministic for a team's success, this article provides a model that aids in the financial decision regarding league expansion or team relocation. This integrative approach effectively captures inter-relationships among factors, as well as the relative importance of each factor. A set of models such as described in this article are not solely applicable to NBA franchise location decisions but can also be used to rank cities for further, more in-depth analysis across many sports and in many countries.

\section{References}

Baim, D.V., \& Sitsky, L. (1994). The sports stadium as a municipal investment. $\mathbf{\square}$ : Greenwood Publishing Group.

Bruggink, T.H., \& Zamparelli, J.M. (1999). Emerging markets in baseball: An econometric model for predicting the expansion teams' new cities. In J. Fizel, E. Gustafson, \& L. Hadley (Eds.), Sports economics: Current research (pp. 55-口). $\mathbf{0}$ : Praeger Press.

Burdekin, R.C., \& Idson, T.L. (1991). Customer preferences, attendances and the racial structure of professional basketball teams. Applied Economics, 23, 179-186.

CSL, Inc. (1999). Feasibility study for baseball in Washington D.C.

Hausman, J.A., \& Leonard, G.K. (1997). Superstars in the National Basketball Association: Economic value and policy. Journal of Labor Economics, 15(4), 586-624.

Hoang, H., \& Rascher, D.A. (1999). The NBA, exit discrimination, and career earnings. Industrial Relations, 38(1),

Klein, B. (1995). The economics of franchise contracts. Journal of Corporate Finance, Contracting, Governance, and Organization, 2(1-2), 9-37.

McDonald, M., \& Rascher, D.A. (2000). Does bat day make cents?: The effect of promotions on the demand for baseball. Journal of Sport Management, 14(1), 8-27.

Rascher, D.A. (1999). A Test of the optimal positive production network externality in Major League Baseball. J. Fizel, E. Gustafson, \& L. Hadley (Eds.), Sports economics: Current research (pp. $\square$ ). $\mathbf{\square}$ : Praeger Press.

Rich, W.C. (2000). The economics and politics of sports facilities. $\mathbf{\square}$ : Quorum Books. Savageau, D. With D’Agostino, R. (2000). Places Rated Almanac (millennium ed.). IDG Books Worldwide, Inc.

\section{Notes}

${ }^{1}$ The third time was a charm for New Orleans. Since losing the Jazz to Utah in 1979, the city had twice attempted to land an NBA team. The NBA blocked an attempt to bring the Minnesota Timberwolves to New Orleans in 1994, and the Vancouver Grizzlies, who the 
city made a major effort to land in 2000 , moved instead to Memphis.

${ }^{2}$ The original teams include the Boston Celtics, Chicago Stags, Cleveland Rebels, Detroit Falcons, New York Knickerbockers, Philadelphia Warriors, Pittsburgh Ironmen, Providence Steamrollers, St. Louis Bombers, Toronto Huskies, and the Washington Capitols. Teams still in existence include the Boston Celtics, New York Knicks, and the Golden State Warriors (by way of Philadelphia and San Francisco).

${ }^{3}$ The American Basketball Association (ABA) existed for nine full seasons from 1967 to 1976. During that time, the ABA competed with the established NBA for players, fans, and media attention. In June 1976, the two rival professional leagues merged, with the four strongest ABA teams (the New York Nets, Denver Nuggets, Indiana Pacers, and San Antonio Spurs) joining the NBA. The other remaining ABA teams vanished, along with the ABA itself.

${ }^{4}$ The Oilers moved from Houston to Memphis, TN, in 1997 but did not change their name to the Titans until the move from Memphis to Nashville in 1999. The NFL then expanded back into Cleveland, in September 1998, forming the Cleveland Browns, and into Houston, whose expansion franchise commenced play in 2002 as the Houston Texans.

${ }^{5}$ The agreement is for a 10-year lease, with the team paying \$2 million annual rent and receiving all the revenue from premium seating, advertising, naming rights, concessions, novelty, and parking - a guarantee of at least $\$ 18$ million in annual arena revenue for the team. The rent is subject to adjustment if attendance is under 11,000 a game but will not drop below $\$ 1$ million. All expenses to move the team were covered by the city of New Orleans, as were all incidentals incurred as a result of the relocation. The team moved into New Orleans Arena, which the city spent \$15 million to upgrade to NBA standards.

New Orleans' median household income is $\$ 38,800$ a year, below the national average and below Charlotte's median income of $\$ 51,000$. New Orleans's TV market, ranked 43rd nationally, is the smallest in the NBA; Charlotte's TV market ranks 27th.

${ }^{6}$ Those teams are the New Orleans Saints (1966), Seattle Seahawks (1974), Tampa Bay Buccaneers (1974), Carolina Panthers (1994), Jacksonville Jaguars (1994), Cleveland Browns (1999), and Houston Texans (2002).

${ }^{7}$ Minnesota Vikings' owner, Red McCombs, said the Vikings cannot remain competitive unless they get a new stadium to replace the Metrodome. Getting a new stadium built for the Vikings was Red McCombs' top priority, but measures to finance a stadium in Minnesota have twice failed. McCombs suggestion that the team relocate to San Antonio is unlikely because San Antonio is another small market in a state with two teams, the Dallas Cowboys and the Houston Texans.

${ }^{8}$ See Baim and Sitsky (1994) and Rich (2000) for an in-depth discussion of the politics of stadium financing.

${ }^{9}$ In 1999 there were 29 teams in the NBA, with two located in Canada (the Vancouver team has recently moved to Memphis, Tennessee), and two each in the Los Angeles and New York areas.

${ }^{10}$ Data for the degree of public financial support for current arenas comes from Turnkey Sports, LLC.

${ }^{11}$ The correlation between city population and the percentage of an arena that was publicly financed is 0.45 , which is significant at the $1 \%$ level.

${ }^{12}$ The choice of the 23 non-NBA cities is simply based on MSA population.

${ }^{13}$ These variables were chosen based on a review of the literature, on the availability of data, and on knowledge regarding the theory of demand. Ultimately, the data will determine their applicability. 
${ }^{14}$ City population variables were derived from U.S. Census data, and MSA population data is from Places Rated Almanac (Savageau, 2000).

${ }^{15}$ The income variables are average pay per worker by MSA (1999), and typical household income by MSA (1999). See Places Rated Almanac (Savageau, 2000).

${ }^{16}$ See Rascher (1999) for a discussion of factors that affect demand at sporting events.

${ }^{17}$ Theses nine items are state income taxes, state and local sales taxes, property taxes, home mortgage or rent, utilities, food, health care, transportation, and recreation. The remaining $40 \%$ is composed of federal income taxes, investments, and miscellaneous goods and services. See Places Rated Almanac (Savageau, 2000).

${ }^{18}$ See Places Rated Almanac (Savageau, 2000).

${ }^{19}$ See Dun \& Bradstreet. Figures were compiled by MSA for companies with more than 25 employees and earning more than $\$ 5$ million in annual revenues, referred to as "Mid-sized Corporations." Also included was a measure compiled by MSA for companies with more than 50 employees and earnings in excess of $\$ 10$ million annually, referred to as "Large Corporations."

${ }^{20}$ Although it is true, however, that distance isolates the franchise from competition, the amount of isolation from competitors also has the negative effect of increasing team travel costs. This article analyzes revenues, not costs. In general, the variation in costs from franchise to franchise is not a function of locational attributes, but relates to decisions regarding team salary and marketing expenditures, for instance. An analysis of profits was considered, but reliable profit data are unavailable.

${ }^{21}$ Bruggink and Zamparelli (1999), p. 55.

${ }^{22}$ This includes: amusement and theme parks, aquariums, auto racing, college sports, gambling, golf courses, good restaurants, movie theater screens, professional sports, protected recreation areas, skiing, water areas, and zoos. See Places Rated Almanac (Savageau, 2000).

${ }^{23}$ The Canadian teams are excluded for lack of comparable data. In excluding the Canadian teams 81 observations are omitted (27 teams for three seasons).

${ }^{24}$ For the corresponding years, in the NFL, the 32 franchises share approximately $80 \%$ of gross revenues. In MLB, teams share approximately $33 \%$ of total revenues, the NBA shares in excess of $35 \%$ of league revenues, and the NHL shares approximately $30 \%$ of total revenues. In most leagues, certain localized revenue streams are exempted from the revenue sharing formula, including revenues generated by the stadium (as opposed to the team), such as premium seating (club seats and luxury suites), sponsorship, parking, and concessions. Stadium-based revenues are increasing at impressive rates, growing more dramatically in recent years because of luxury suites, naming rights, etc. Hence, the recent boom in stadium construction is primarily in response to these revenue-sharing exemptions. The level of an individual team's financial success is dependant on the team's ability to capitalize on the local market in terms of stadium economics.

${ }^{25}$ The actual reported gate receipts are for the year 1999.

${ }^{26}$ This data comes from the Fan Cost Index ${ }^{\mathrm{TM}}$ published annually by Team Marketing Report.

${ }^{27}$ To create a fair forecast, however, all cities were assumed to have a winning percentage of 0.500 , given that non-NBA cities do not have a winning percentage at all.

${ }^{28}$ For example, see Burdekin and Idson (1991), Hausman and Leonard (1997), Hoang and Rascher (1999), and McDonald and Rascher (2000).

${ }^{29}$ Winning percentage is not exactly at 0.500 because the data does not include the two Canadian teams who have subpar records.

${ }^{30}$ See CSL, Inc. (1999). 
${ }^{31}$ Prices were not found to be an important factor (except to the extent that there was multicollinearity) in forecasting attendance, with no $t$ statistic exceeding .40. Cost of living, all-star votes, and distance to nearest NBA city also proved to be insignificant predictors of attendance and revenue.

${ }^{32}$ Results shown are for the 1999-2000 NBA season. The Lakers and Clippers have the same forecast because the variables in the model are market specific, and therefore the same for both teams. The only difference among teams sharing a locale is winning percentage, and, in this table, all teams' winning percentages were set to 0.500 in order to create comparable forecasts for cities without NBA teams (which do not have a corresponding winning percentage).

${ }^{33}$ Memphis had attracted enough investors to buy a $49 \%$ interest in the team, whereas Louisville investors were only able to offer a $20 \%$ stake in the team. FedEx helped to seal the deal for Memphis by agreeing to pay $\$ 100$ million for naming rights for a new stadium in Memphis and the team (Memphis Express), matching the offer of Tricon Global Restaurants (parent company of Kentucky Fried Chicken, Pizza Hut and Taco Bell) that reportedly offered \$100 million for the naming rights of the new arena.

${ }^{34} \mathrm{We}$ thank one of the reviewers for noting this use of the model. 